\title{
Review Article \\ The Role of MIF in Type 1 and Type 2 Diabetes Mellitus
}

\author{
Yuriko I. Sánchez-Zamora and Miriam Rodriguez-Sosa \\ Unidad de Biomedicina, Facultad de Estudios Superiores-Iztacala, Universidad Nacional Autónoma de México, \\ Avenida de los Barrios No. 1, Los Reyes Iztacala, 54090 Tlalnepantla, MEX, Mexico \\ Correspondence should be addressed to Miriam Rodriguez-Sosa; rodriguezm@campus.iztacala.unam.mx
}

Received 9 October 2013; Accepted 11 December 2013; Published 2 January 2014

Academic Editor: Alfredo Vannacci

Copyright ( 2014 Y. I. Sánchez-Zamora and M. Rodriguez-Sosa. This is an open access article distributed under the Creative Commons Attribution License, which permits unrestricted use, distribution, and reproduction in any medium, provided the original work is properly cited.

\begin{abstract}
Autoimmunity and chronic low-grade inflammation are hallmarks of diabetes mellitus type one (T1DM) and type two (T2DM), respectively. Both processes are orchestrated by inflammatory cytokines, including the macrophage migration inhibitory factor (MIF). To date, MIF has been implicated in both types of diabetes; therefore, understanding the role of MIF could affect our understanding of the autoimmune or inflammatory responses that influence diabetic pathology. This review highlights our current knowledge about the involvement of MIF in both types of diabetes in the clinical environment and in experimental disease models.
\end{abstract}

\section{Introduction}

MIF was originally reported in 1966 by two different groups and was described as a $\mathrm{T}$ cell derived cytokine that inhibited the random migration of macrophages in vitro and promoted macrophage accumulation during delayed-type hypersensitivity reactions $[1,2]$. Human and mouse MIF genes are 90\% homologous; MIF protein has a molecular weight of $12.5 \mathrm{kDa}$ [3]. MIF is an evolutionarily conserved molecule that is constitutively expressed in many tissues and cells (Figure 1).

Moreover, MIF is stored in intracellular pools and therefore does not require immediate synthesis before secretion. MIF lacks an aminoterminal leader sequence; this indicates that MIF is released from cells through a nonconventional protein-secretion pathway [3].

After the discovery of MIF, several studies were conducted to establish its role in the immune response [4-6]. However, not until 1990 was MIF recognized as the first molecule to arrive at the inflammation site and the factor that likely determines the degree of cellular inflammation [7]. Different experimental strategies, including anti-MIF antibodies and knockout (KO) and transgenic MIF mice (MIF-Tg), have been used to establish that MIF counterregulates the immunosuppressive effects of steroids and to implicate MIF in tumor necrosis factor $(\mathrm{TNF} \alpha)$ and nitric oxide $(\mathrm{NO})$ production [8]; additionally, MIF was found to possess growth factor activity [9], overregulate the expression of Toll-like receptor
(TLR)-4 on antigen-presenting cells [10], sustain macrophage proinflammatory abilities by inhibiting $\mathrm{p} 53$, and also possess tautomerase and oxidoreductase activities [11].

All the above-described inherent properties permitted the recognition of MIF as a critical molecule in proinflammatory innate immune responses and the restriction of certain parasite infections [12-14]. Additionally, MIF involvement has been demonstrated in immunological and inflammatory diseases $[15,16]$ such as septic shock [17], cancer [18], and chronic diseases including bowel disease [19], rheumatoid arthritis [20-22], colitis [23], obesity [24-26], and diabetes $[25,27,28]$. More recently, MIF was proposed as a diagnostic biomarker for autoimmune diseases such as arthritis, ulcerative colitis, and diabetes $[23,29,30]$.

In this review, we will focus on some of the properties that have been conferred upon MIF with regard to the development and maintenance of T1DM and T2DM. We will discuss the data that have been collected in clinical studies and studies of MIF-KO mice and other protocols in which MIF has been proposed as a therapeutic diabetes mellitus pathological target.

\section{MIF and Diabetes}

2.1. Diabetes. This disease comprises a group of metabolic diseases that are characterized by hyperglycemia, which is 


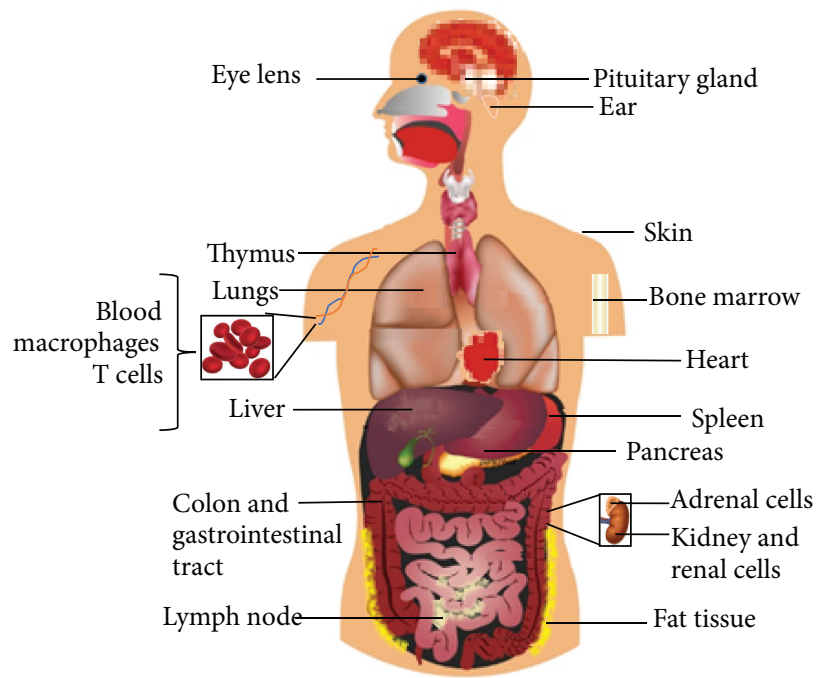

FIGURE 1: MIF expression pattern. MIF, a cytokine, is distributed throughout almost the entire body. This is because MIF is part of the innate immune system or first line of immune defense.

associated with damage to and/or malfunction or failure of various organs, including the eyes, kidneys, nerves, heart, and blood vessels, among others. The causes of this disease range from autoimmune or metabolic abnormalities to deficiencies in insulin activity and secretion [31]. Currently, there is no cure for this chronic degenerative disease; however, the constant development of knowledge helps us to better understand the disease etiology and potential therapeutical targets that, when combined, could lead to good symptom and disease control [31].

\subsection{MIF and TIDM or Insulin-Dependent Diabetes Mellitus} (IDDM). According to the American Diabetes Association, T1DM patients comprise only $5-10 \%$ of those with diabetes [26]. This disease is a multifactorial, organ-specific autoimmune disease that occurs in genetically susceptible individuals [32]. T1DM is the result of the autoimmune destruction of pancreatic islet $\beta$ cells by infiltrating immune cells (insulitis); this occurs due to a failure in immune tolerance because the organism has had contact with specific viruses [33] such as cytomegalovirus [34] or with food molecules that caused molecular mimicry [35]. The common autoantigens recognized in this disease are insulin, glutamate decarboxylase 65 (GAD65), and the islet antigens IA-2 and IA- $2 \beta[36,37]$. During insulitis, high levels of proinflammatory cytokines, including IL- $1 \beta$, TNF $\alpha$, IL- 12 , MIF, and IFN $\gamma$, are secreted by effector T cells to trigger the $\beta$ cell destruction process [32]. MIF is considered one of the most common factors in autoimmunity [38]. In humans with T1DM, blood MIF concentrations were found to be high, compared to those in healthy controls [39]; normal plasma MIF concentrations in healthy humans range from 2.3 to $8.4 \mathrm{ng} / \mathrm{mL}$ [40]. In contrast, plasma MIF concentrations dramatically change from $5 \mathrm{ng} / \mathrm{mL}$ to $1 \mathrm{ng} / \mathrm{mL}$ after islet transplantation [41]. Also high MIF concentrations are associated with a subsequent loss of islet graft function [41]. IL-1 $\beta$ and TNF- $\alpha$ are expressed at high levels along with advanced type one diabetes complications such as ketoacidosis [42], and thus it is possible that high levels of MIF are also expressed at this point in the disease. MIF studies were facilitated by the development of MIF-KO mice in 1999 [43]. Using these mice as an efficient tool, MIF was shown to be an important molecule in early syngeneic islet transplantation function, and blocking of MIF resulted in transplant success [44]. Additionally, we know that MIF participates in TIDM by controlling the functional activities of monocytes/macrophages and $\mathrm{T}$ cells and modulating their abilities to secrete proinflammatory molecules [45]. Furthermore, MIF has been recognized as important molecule to the development of T1DM complications such as cardiac dysfunction, which is associated with AMPK signaling [46], and diabetic foot disease [47] and is known to promote inflammatory cytokine and palmitic acid-induced pancreatic islet apoptosis $[48,49]$. After successful antibody and pharmacological inhibitor-mediated MIF neutralization, MIF was proposed as a new target strategy for the treatment of T1DM $[45,50]$.

The involvement of MIF in T1DM is summarized in Figure 2. With the above-outlined information, we can conclude that the participation of MIF in the pathology of TIDM is a well-documented fact; however, we do not know the exact point in disease development at which MIF exerts the most influence. Considering that the insulitis process marks the beginning of the disease and is an autoimmune inflammatory process, we propose the hypothesis that MIF plays an important role in insulitis onset or development. This hypothesis is supported by studies in which MIF was found to play important roles in the processes of antigen presentation and inflammatory cell activation $[13,51]$. However, additional studies should be performed to establish the mechanism related to the role of MIF in T1DM.

2.3. MIF and T2DM or Noninsulin-Dependent Diabetes Mellitus (NIDDM). T2DM patients account for $90-95 \%$ of all diabetic patients, and this disease is characterized by the presence of insulin resistance and, usually, relative insulin deficiency. The most common risk factors for this type of diabetes are genetic conditions, obesity, lifestyle, and eating habits. Therefore involvement of the inflammatory response is equally important in disease development, hence the reason why the role of MIF has been studied most in T2DM [31].

Several clinical studies have shown that the serum MIF levels are elevated in patients with T2DM [52]. In 2006, high blood MIF levels were suggested to precede the onset of T2DM [40]. More recently, both patients with T2DM and those with impaired glucose tolerance were shown to have significantly elevated MIF serum levels [25, 27, 53]. Some data report normal plasma MIF concentrations in healthy humans to range from 2.3 to $8.4 \mathrm{ng} / \mathrm{mL}$ [35]. In contrast, plasma MIF concentrations from T2DM subjects range from 7.3 to $15.8 \mathrm{ng} / \mathrm{mL}$. As in T1DM, MIF is highly expressed in T2DM complications such as myocardial damage [54], coronary artery disease [53], diabetic retinopathy [55], obesity [56], 


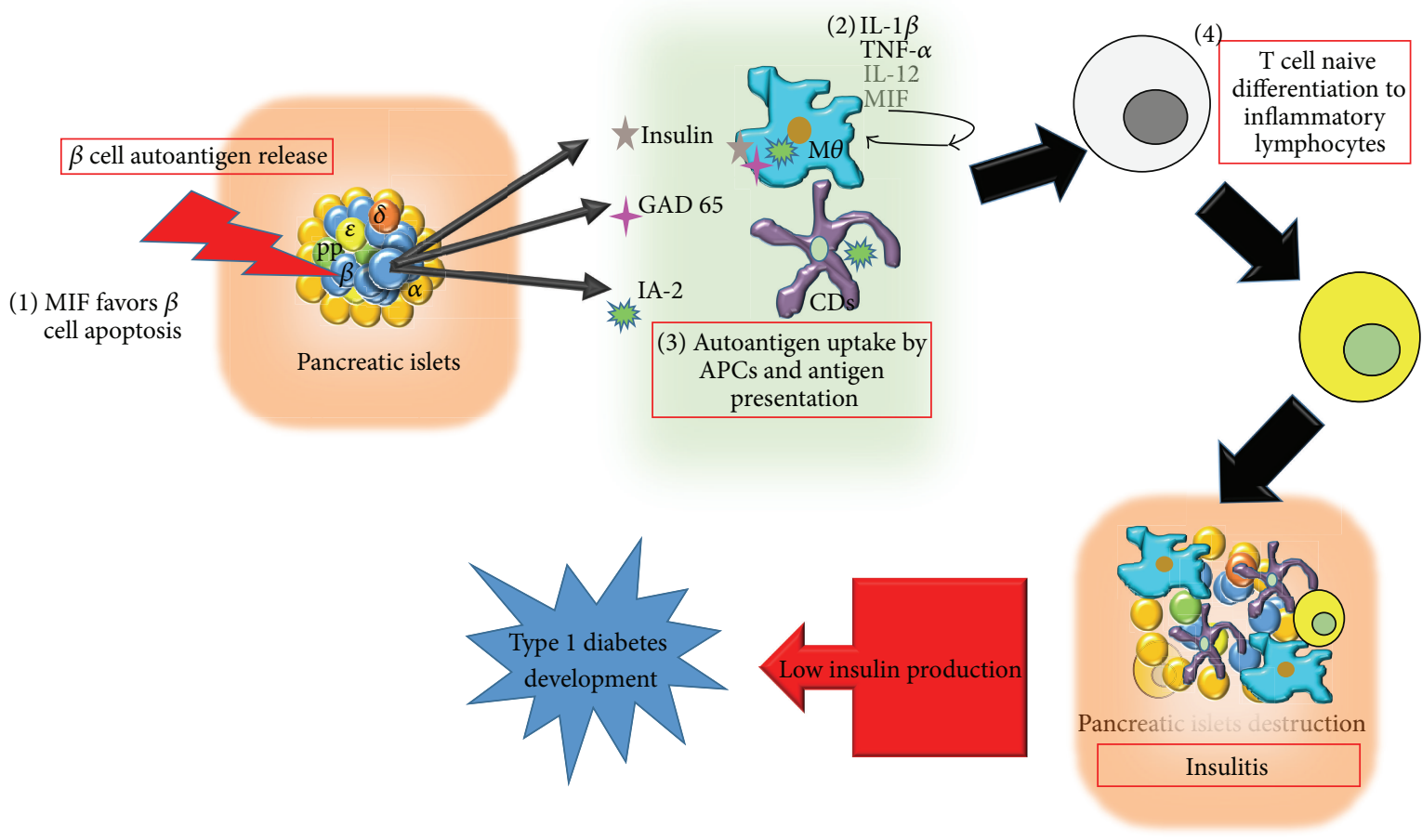

FIGURE 2: MIF involvement in T1DM development. (1) MIF promotes pancreatic $\beta$ cell apoptosis. (2) MIF promotes the production of inflammatory cytokines such as IL-1 $\beta$, TNF- $\alpha$, and IL-12. (3) MIF favors autoantigen presentation. (4) MIF promotes the activation of an inflammatory response, leading to insulitis.

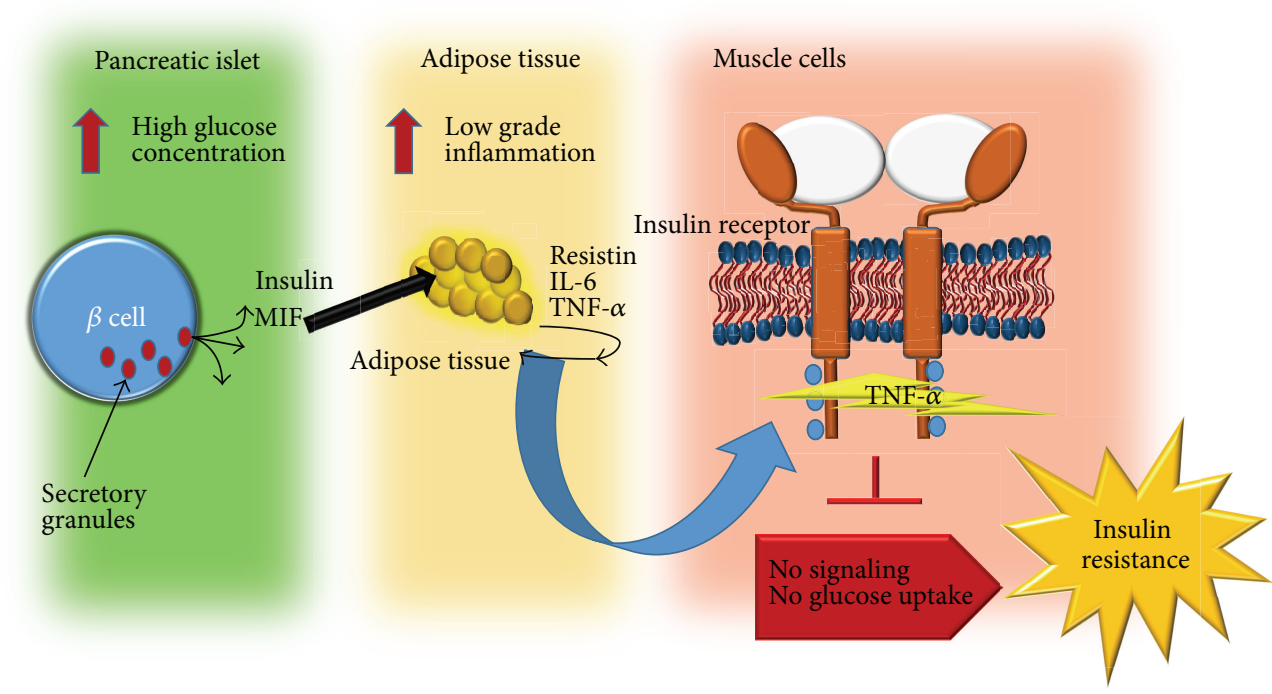

FIGURE 3: MIF plays an indirect role in T2DM development by promoting the production of proinflammatory cytokines and adipocytokines that are involved in insulin receptor signaling, leading to insulin resistance.

and metabolic syndrome [57]. The role of MIF in T2DM has been studied in murine models. Using $\mathrm{db} / \mathrm{db}$ mice, MIF was suggested as a factor that could initiate the onset of microalbuminuria in diabetic nephropathy [58]. MIF plays an important role in the chronic, obesity-associated adipose tissue inflammation that leads to the development of insulin resistance in MIF-KO mice [59]. Additionally, we previously demonstrated in a NIDDM mice model that MIF could be a therapeutic target for disease treatment. Indeed, two candidate drugs (synthetic inhibitors for MIF) for diabetes treatment were described as very effective in the control of the systemic inflammation and the control of some diabetes symptoms [60]. Additionally, we showed that MIF is important to the production of some adipocytokines such as 
resistin, which is the most important adipocytokine in the development of insulin resistance [60]. In this type of diabetes, MIF has been suggested to contribute to the disease in an indirect form due to its ability to stimulate the production of other inflammatory cytokines that directly cause damage to muscle cells. This is true for TNF- $\alpha$, which acts on the insulin receptor and prevents the dephosphorylation of insulin receptor substrates, thus blocking receptor signaling and preventing glucose entry into the cell (insulin resistance). Furthermore, MIF also stimulates the production of certain inflammatory adipocytokines, such as resistin and IL-6, which are key molecules in the development of insulin resistance. As demonstrated, MIF influences T2DM development at different levels. In the pancreas, adipose tissue, and muscle cells, the pleiotropic characteristics of MIF are reflected in the different routes that lead to insulin resistance (Figure 3).

\section{MIF and Pancreatic Beta Cells ( $\beta$ Cells)}

MIF was shown to colocalize in secretory insulin granules within $\beta$ cells and to be released during both phases of insulin secretion. Most importantly, in this regard, MIF appears to have an autocrine, glucose-dependent regulatory effect on insulin secretion [45].

While MIF is related to insulin secretion under homeostatic conditions, altered homeostasis in an organism (such as the presence of inflammation) apparently induces MIF to act differently and become a destructive molecule that can lead to $\beta$ cell apoptosis $[48,61]$. Apparently, MIF is not a foreign molecule in the pancreatic $\beta$ cell microenvironment and can act in response to the concentration of glucose and the presence of inflammation.

\section{Conclusions}

Previously, different models were used to show that MIF is a pleiotropic molecule [62-64], and this property is very evident in pancreatic islets. Due to the large number of studies that support this idea, we can conclude that MIF is a proinflammatory cytokine with great importance not only during the course of diabetes but also before the establishment of diabetes and in the risk factors of disease such as obesity. We support the statement that MIF is a therapeutic target and propose that it is necessary to design synthetic MIF inhibitors that could interact with the existing therapies used to treat diabetes.

\section{Conflict of Interests}

The authors declare that there is no conflict of interests.

\section{Acknowledgments}

The authors thank M. S. Imelda Juarez for collecting the items required for this paper. National Council of Science and Technology (CONACYT), Mexico, supported Ph.D. fellowship for Yuriko I. Sánchez-Zamora (no. 349680) and this review is a requirement to obtain her degree in Biomedical
Sciences, UNAM. The author's research was supported by the Grants UNAM-DGAPA-PAPIIT (IN212412), Miguel Aleman Foundation, and CONACyT-152224.

\section{References}

[1] B. R. Bloom and B. Bennett, "Mechanism of a reaction in vitro associated with delayed-type hypersensitivity," Science, vol. 153, no. 3731, pp. 80-82, 1966.

[2] J. R. David, "Delayed hypersensitivity in vitro: its mediation by cell-free substances formed by lymphoid cell-antigen interaction," Proceedings of the National Academy of Sciences of the United States of America, vol. 56, no. 1, pp. 72-77, 1966.

[3] T. Calandra and T. Roger, "Macrophage migration inhibitory factor: a regulator of innate immunity," Nature Reviews Immunology, vol. 3, no. 10, pp. 791-800, 2003.

[4] P. Kotkes and E. Pick, "Studies on guinea-pig macrophage migration inhibitory factor (MIF). I. Glycoprotein nature and net charge," Clinical and Experimental Immunology, vol. 37, no. 3, pp. 532-539, 1979.

[5] N. I. Sotnikova and L. V. Koval'chuk, "Role of the thymus in regulation of the macrophage migration inhibitory factor production in mice of different genotypes," Byulleten Eksperimentalnoi Biologii i Meditsiny, vol. 88, no. 9, pp. 311-314, 1979.

[6] G. P. Cavallo and S. Landolfo, "Biologic aspects of macrophage migration inhibitory factor," Giornale di Batteriologia Virologia ed Immunologia, vol. 73, no. 7-12, pp. 196-201, 1980.

[7] U. Malorny, M. Goebeler, J. Gutwald, J. Roth, and C. Sorg, "Differences in migration inhibitory factor production by $\mathrm{C} 57 \mathrm{Bl} / 6$ and BALB/c mice in allergic and iritant contact dermatitis," International Archives of Allergy and Applied Immunology, vol. 92, no. 4, pp. 356-360, 1990.

[8] Y. P. de Jong, A. C. Abadia-Molina, A. R. Satoskar et al., "Development of chronic colitis is dependent on the cytokine MIF," Nature Immunology, vol. 2, no. 11, pp. 1061-1066, 2001.

[9] R. Abe, T. Shimizu, A. Ohkawara, and J. Nishihira, "Enhancement of macrophage migration inhibitory factor (MIF) expression in injured epidermis and cultured fibroblasts," Biochimica et Biophysica Acta, vol. 1500, no. 1, pp. 1-9, 2000.

[10] T. Roger, C. Froidevaux, C. Martin, and T. Calandra, "Macrophage migration inhibitory factor (MIF) regulates host responses to endotoxin through modulation of toll-like receptor 4 (TLR4)," Journal of Endotoxin Research, vol. 9, no. 2, pp. 119123, 2003.

[11] H. Sugimoto, M. Taniguchi, A. Nakagawa, I. Tanaka, M. Suzuki, and J. Nishihira, "Crystal structure of human D-Dopachrome tautomerase, a homologue of macrophage migration inhibitory factor, at $1.54 \AA$ resolution," Biochemistry, vol. 38, no. 11, pp. 3268-3279, 1999.

[12] C. A. Terrazas, I. Juarez, L. I. Terrazas, R. Saavedra, E. A. Calleja, and M. Rodriguez-Sosa, "Toxoplasma gondii: impaired maturation and pro-inflammatory response of dendritic cells in MIFdeficient mice favors susceptibility to infection," Experimental Parasitology, vol. 126, no. 3, pp. 348-358, 2010.

[13] M. Flores, R. Saavedra, R. Bautista et al., "Macrophage migration inhibitory factor (MIF) is critical for the host resistance against Toxoplasma gondii," FASEB Journal, vol. 22, no. 10, pp. 3661-3671, 2008.

[14] J. L. Reyes, L. I. Terrazas, B. Espinoza et al., "Macrophage migration inhibitory factor contributes to host defense against acute Trypanosoma cruzi Infection," Infection and Immunity, vol. 74, no. 6, pp. 3170-3179, 2006. 
[15] P. Renner, T. Roger, and T. Calandra, "Macrophage migration inhibitory factor: gene polymorphisms and susceptibility to inflammatory diseases," Clinical Infectious Diseases, vol. 41, supplement 7, pp. S513-S519, 2005.

[16] A. Y. Hoi, M. N. Iskander, and E. F. Morand, "Macrophage migration inhibitory factor: a therapeutic target across inflammatory diseases," Inflammation and Allergy-Drug Targets, vol. 6, no. 3, pp. 183-190, 2007.

[17] R. A. Mitchell, H. Liao, J. Chesney et al., "Macrophage migration inhibitory factor (MIF) sustains macrophage proinflammatory function by inhibiting $\mathrm{p} 53$ : regulatory role in the innate immune response," Proceedings of the National Academy of Sciences of the United States of America, vol. 99, no. 1, pp. 345-350, 2002.

[18] S. N. Babu, G. Chetal, and S. Kumar, "Macrophage migration inhibitory factor: a potential marker for cancer diagnosis and therapy," Asian Pacific Journal of Cancer Prevention, vol. 13, no. 5, pp. 1737-1744, 2012.

[19] J. Nishihira, "Molecular function of macrophage migration inhibitory factor and a novel therapy for inflammatory bowel disease," Annals of the New York Academy of Sciences, vol. 1271, pp. 53-57, 2012.

[20] R. Liu, N. Xu, X. Wang et al., "Influence of MIF, CD40, and CD226 polymorphisms on risk of rheumatoid arthritis," Molecular Biology Reports, vol. 39, no. 6, pp. 6915-6922, 2012.

[21] M. Liu and C. Hu, "Association of MIF in serum and synovial fluid with severity of knee osteoarthritis," Clinical Biochemistry, vol. 45, no. 10-11, pp. 737-739, 2012.

[22] M. A. Llamas-Covarrubias, Y. Valle, R. E. Navarro-Hernández et al., "Serum levels of macrophage migration inhibitory factor are associated with rheumatoid arthritis course," Rheumatology International, vol. 32, no. 8, pp. 2307-2311, 2012.

[23] G. Sivaram, S. K. Tiwari, A. Bardia et al., "Macrophage migration inhibitory factor, toll-like receptor 4 , and CD14 polymorphisms with altered expression levels in patients with ulcerative colitis," Human Immunology, vol. 73, no. 2, pp. 201-205, 2012.

[24] S. Sohlberg, "Personality, life stress and the course of eating disorders," Acta Psychiatrica Scandinavica, Supplementum, vol. 82, no. 361, pp. 29-33, 1990.

[25] R. Kleemann and R. Bucala, "Macrophage migration inhibitory factor: critical role in obesity, insulin resistance, and associated comorbidities," Mediators of Inflammation, vol. 2010, Article ID 610479, 7 pages, 2010.

[26] J. N. Fain, "Release of interleukins and other inflammatory cytokines by human adipose tissue is enhanced in obesity and primarily due to the nonfat cells," Vitamins and Hormones, vol. 74, pp. 443-477, 2006.

[27] O. M. Finucane, C. M. Reynolds, F. C. McGillicuddy, and H. M. Roche, "Insights into the role of macrophage migration inhibitory factor in obesity and insulin resistance," The Proceedings of the Nutrition Society, vol. 71, no. 4, pp. 622-633, 2012.

[28] I. Stojanovic, T. Saksida, and S. Stosic-Grujicic, "Beta cell function: the role of macrophage migration inhibitory factor," Immunologic Research, vol. 52, no. 1-2, pp. 81-88, 2012.

[29] G. Grieb, M. Merk, J. Bernhagen, and R. Bucala, "Macrophage migration inhibitory factor (MIF): a promising biomarker," Drug News and Perspectives, vol. 23, no. 4, pp. 257-264, 2010.

[30] B. Miterski, S. Drynda, G. Böschow et al., "Complex genetic predisposition in adult and juvenile rheumatoid arthritis," $B M C$ Genetics, vol. 5, article 2, 2004.
[31] American Diabetes Association, "Diagnosis and classification of diabetes mellitus," Diabetes Care, vol. 33, supplement 1, pp. S62-S69, 2010.

[32] B. Baumann, H. H. Salem, and B. O. Boehm, "Anti-inflammatory therapy in type 1 diabetes," Current Diabetes Reports, vol. 12, no. 5, pp. 499-509, 2012.

[33] L. Galleri, G. Sebastiani, F. Vendrame, F. A. Grieco, I. Spagnuolo, and F. Dotta, "Viral infections and diabetes," Advances in Experimental Medicine and Biology, vol. 771, pp. 252-271, 2012.

[34] K. Osame, Y. Takahashi, H. Takasawa et al., "Rapid-onset type 1 diabetes associated with cytomegalovirus infection and islet autoantibody synthesis," Internal Medicine, vol. 46, no. 12, pp. 873-877, 2007.

[35] J. F. Bach, "Insulin-dependent diabetes mellitus as an autoimmune disease," Endocrine Reviews, vol. 15, no. 4, pp. 516-542, 1994.

[36] T. Orban and J. T. Kis, "Prevention of type 1 diabetes mellitus using a novel vaccine," Therapeutic Advances in Endocrinology and Metabolism, vol. 2, no. 1, pp. 9-16, 2011.

[37] R. Mallone, V. Brezar, and C. Boitard, "T cell recognition of autoantigens in human type 1 diabetes: clinical perspectives," Clinical and Developmental Immunology, vol. 2011, Article ID 513210, 16 pages, 2011.

[38] B. Rueda, G. Orozco, E. Sánchez, J. Oliver, and J. Martín, “Common genetic factors in autoimmunity," Reumatologia Clinica, vol. 4, supplement 1, pp. 1-4, 2008.

[39] P. Hanifi-Moghaddam, N. C. Schloot, S. Kappler, J. Seißler, and H. Kolb, "An association of autoantibody status and serum cytokine levels in type 1 diabetes," Diabetes, vol. 52, no. 5, pp. 1137-1142, 2003.

[40] C. Herder, H. Kolb, W. Koenig et al., "Association of systemic concentrations of macrophage migration inhibitory factor with impaired glucose tolerance and type 2 diabetes: results from the cooperative health research in the region of Augsburg, survey 4 (KORA S4)," Diabetes Care, vol. 29, no. 2, pp. 368-371, 2006.

[41] C. Pfleger, N. C. Schloot, M. D. Brendel et al., "Circulating cytokines are associated with human islet graft function in type 1 diabetes," Clinical Immunology, vol. 138, no. 2, pp. 154-161, 2011.

[42] Y. Dogan, S. Akarsu, B. Ustundag, E. Yilmaz, and M. K. Gurgoze, "Serum IL-1 $\beta$, IL-2, and IL-6 in insulin-dependent diabetic children," Mediators of Inflammation, vol. 2006, Article ID 59206, 6 pages, 2006.

[43] M. Bozza, A. R. Satoskar, G. Lin et al., "Targeted disruption of migration inhibitory factor gene reveals its critical role in sepsis," Journal of Experimental Medicine, vol. 189, no. 2, pp. 341346, 1999.

[44] C. Toso, V. Serre-Beinier, J. Emamaullee et al., "The role of macrophage migration inhibitory factor in mouse islet transplantation," Transplantation, vol. 86, no. 10, pp. 1361-1369, 2008.

[45] S. Stosic-Grujicic, I. Stojanovic, D. Maksimovic-Ivanic et al., "Macrophage migration inhibitory factor (MIF) is necessary for progression of autoimmune diabetes mellitus," Journal of Cellular Physiology, vol. 215, no. 3, pp. 665-675, 2008.

[46] C. Tong, A. Morrison, X. Yan et al., "Macrophage migration inhibitory factor deficiency augments cardiac dysfunction in type 1 diabetic murine cardiomyocytes," Journal of Diabetes, vol. 2, no. 4, pp. 267-274, 2010.

[47] B. Tchakonté, A. Ndip, P. Aubry, D. Malvy, and J. C. Mbanya, "The diabetic foot in Cameroon," Bulletin de la Societe de Pathologie Exotique, vol. 98, no. 2, pp. 94-98, 2005. 
[48] I. Stojanovic, T. Saksida, I. Nikolic, F. Nicoletti, and S. StosicGrujicic, "Macrophage migration inhibitory factor deficiency protects pancreatic islets from cytokine-induced 20 apoptosis in vitro," Clinical and Experimental Immunology, vol. 169, no. 2, pp. 156-163, 2012.

[49] T. Saksida, S. Stosic-Grujicic, G. Timotijevic, S. Sandler, and I. Stojanovic, "Macrophage migration inhibitory factor deficiency protects pancreatic islets from palmitic acid-induced apoptosis," Immunology and Cell Biology, vol. 90, no. 7, pp. 688-698, 2012.

[50] I. Cvetkovic, Y. Al-Abed, D. Miljkovic et al., "Critical role of macrophage migration inhibitory factor activity in experimental autoimmune diabetes," Endocrinology, vol. 146, no. 7, pp. 2942-2951, 2005.

[51] C. A. Terrazas, E. Huitron, A. Vazquez et al., "MIF synergizes with Trypanosoma cruzi antigens to promote efficient dendritic cell maturation and IL-12 production via p38 MAPK," International Journal of Biological Sciences, vol. 7, no. 9, pp. 1298-1310, 2011.

[52] C. Toso, J. A. Emamaullee, S. Merani, and A. M. J. Shapiro, "The role of macrophage migration inhibitory factor on glucose metabolism and diabetes," Diabetologia, vol. 51, no. 11, pp. 19371946, 2008.

[53] A. Makino, T. Nakamura, M. Hirano et al., "High plasma levels of macrophage migration inhibitory factor are associated with adverse long-term outcome in patients with stable coronary artery disease and impaired glucose tolerance or type 2 diabetes mellitus," Atherosclerosis, vol. 213, no. 2, pp. 573-578, 2010.

[54] X. Y. Yu, H. M. Chen, J. L. Liang et al., "Hyperglycemic myocardial damage is mediated by proinflammatory cytokine: macrophage migration inhibitory factor," PLoS ONE, vol. 6, no. 1, Article ID e16239, 2011.

[55] Y. Mitamura, S. Takeuchi, A. Matsuda, Y. Tagawa, Y. Mizue, and J. Nishihira, "Macrophage migration inhibitory factor levels in the vitreous of patients with proliferative diabetic retinopathy," The British Journal of Ophthalmology, vol. 84, no. 6, pp. 636-639, 2000.

[56] U. Kamchybekov, H. R. Figulla, N. Gerdes, and C. Jung, "Macrophage migration inhibitory factor is elevated in obese adolescents," Archives of Physiology and Biochemistry, vol. 118, no. 4, pp. 204-209, 2012.

[57] H. Kim, S. Lee, H. J. Kim et al., "Elevated levels of macrophage migration inhibitory factor in women with metabolic syndrome," Hormone and Metabolic Research, vol. 43, no. 9, pp. 642-645, 2011.

[58] T. Watanabe, N. H. Tomioka, M. Doshi, S. Watanabe, M. Tsuchiya, and M. Hosoyamada, "Macrophage migration inhibitory factor is a possible candidate for the induction of microalbuminuria in diabetic $\mathrm{db} / \mathrm{db}$ mice," Biological and Pharmaceutical Bulletin, vol. 36, no. 5, pp. 741-747, 2013.

[59] L. Verschuren, T. Kooistra, J. Bernhagen et al., "MIF deficiency reduces chronic inflammation in white adipose tissue and impairs the development of insulin resistance, glucose intolerance, and associated atherosclerotic disease," Circulation Research, vol. 105, no. 1, pp. 99-107, 2009.

[60] Y. Sanchez-Zamora, L. I. Terrazas, A. Vilches-Flores et al., "Macrophage migration inhibitory factor is a therapeutic target in treatment of non-insulin-dependent diabetes mellitus," FASEB Journal, vol. 24, no. 7, pp. 2583-2590, 2010.

[61] I. Stojanovic, T. Saksida, G. Timotijevic, S. Sandler, and S. StosicGrujicic, "Macrophage migration inhibitory factor (MIF) enhances palmitic acid-and glucose-induced murine beta cell dysfunction and destruction in vitro," Growth Factors, vol. 30, no. 6, pp. 385-393, 2012.

[62] Y. Al-Abed and S. van Patten, "MIF as a disease target: ISO-1 as a proof-of-concept therapeutic," Future Medicinal Chemistry, vol. 3, no. 1, pp. 45-63, 2011.

[63] C. Maaser, L. Eckmann, G. Paesold, H. S. Kim, and M. F. Kagnoff, "Ubiquitous production of macrophage migration inhibitory factor by human gastric and intestinal epithelium," Gastroenterology, vol. 122, no. 3, pp. 667-680, 2002.

[64] F. Wang, F. Gao, and L. Jing, "Is macrophage migration inhibitory factor (MIF) the "control point" of vascular hyporesponsiveness in septic shock?" Medical Hypotheses, vol. 65, no. 6, pp. 1082-1087, 2005. 


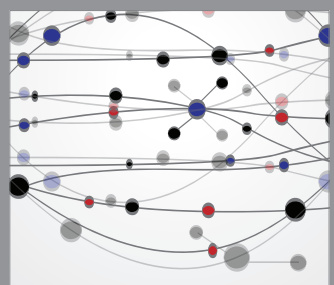

The Scientific World Journal
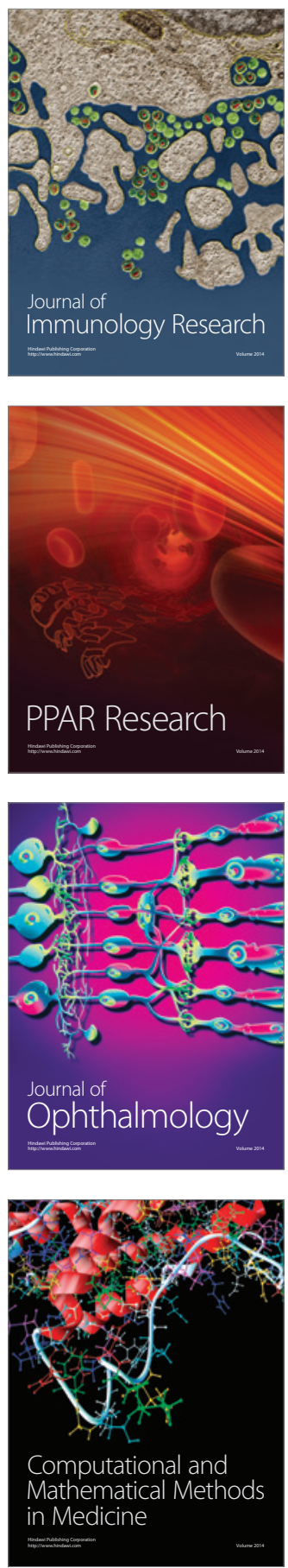

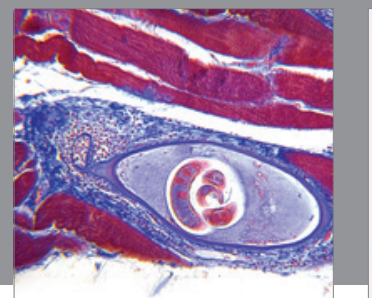

Gastroenterology

Research and Practice
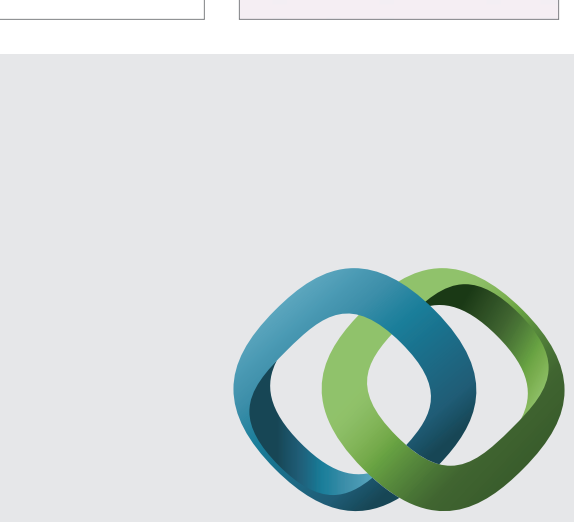

\section{Hindawi}

Submit your manuscripts at

http://www.hindawi.com
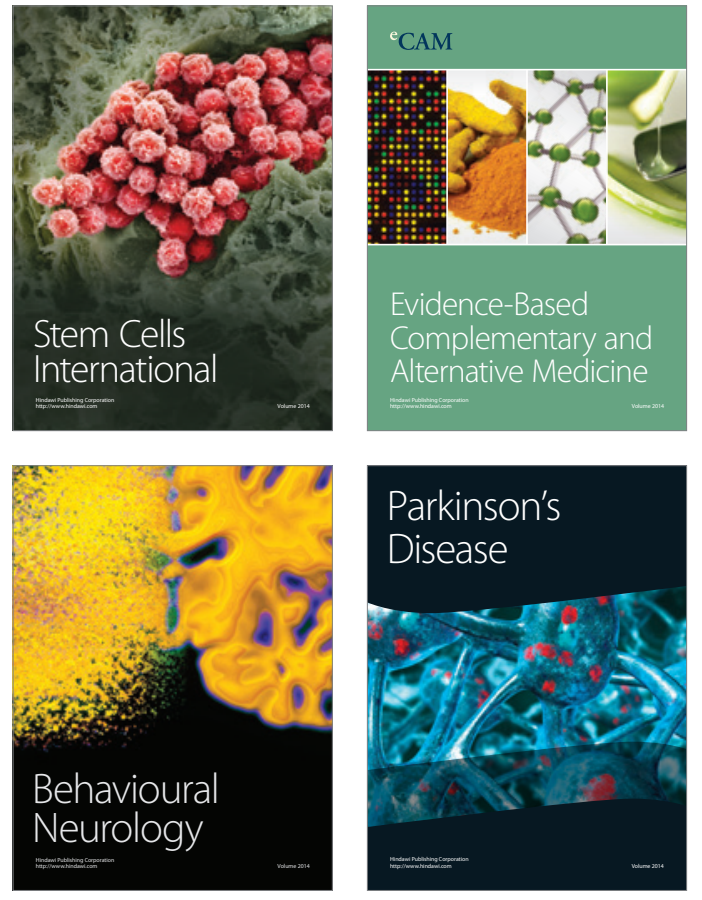
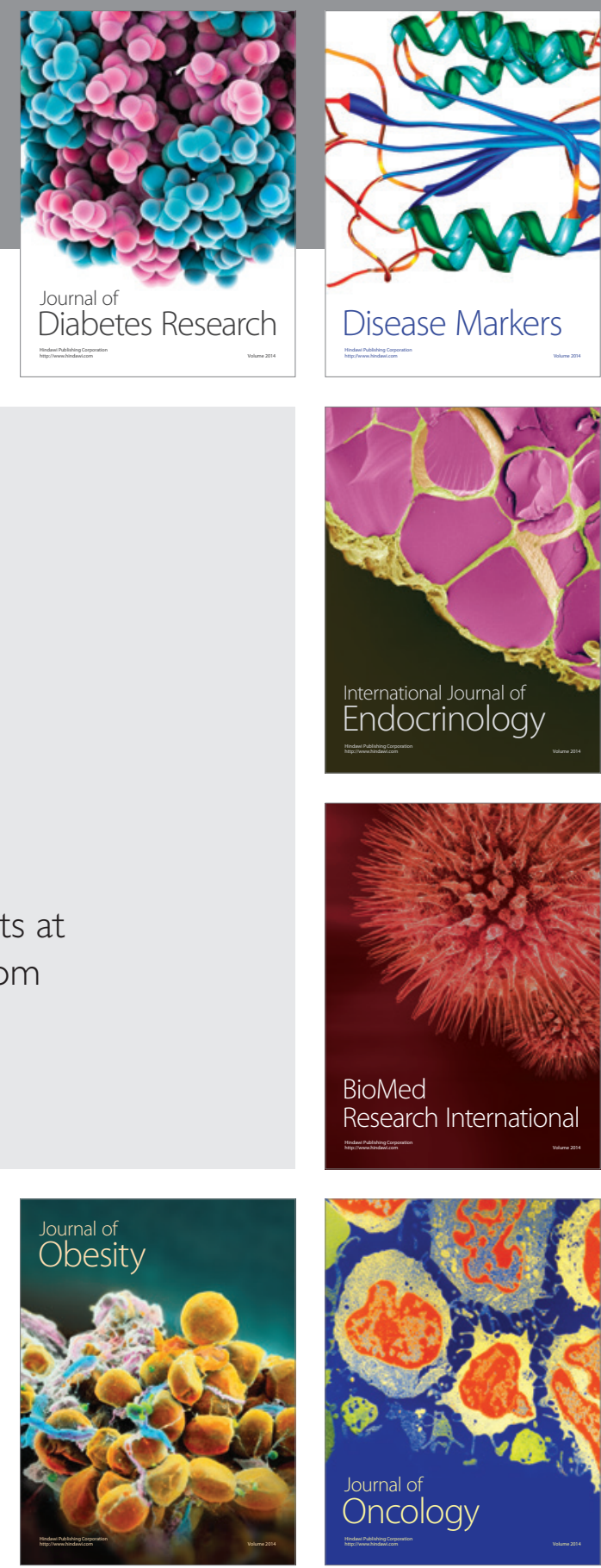

Disease Markers
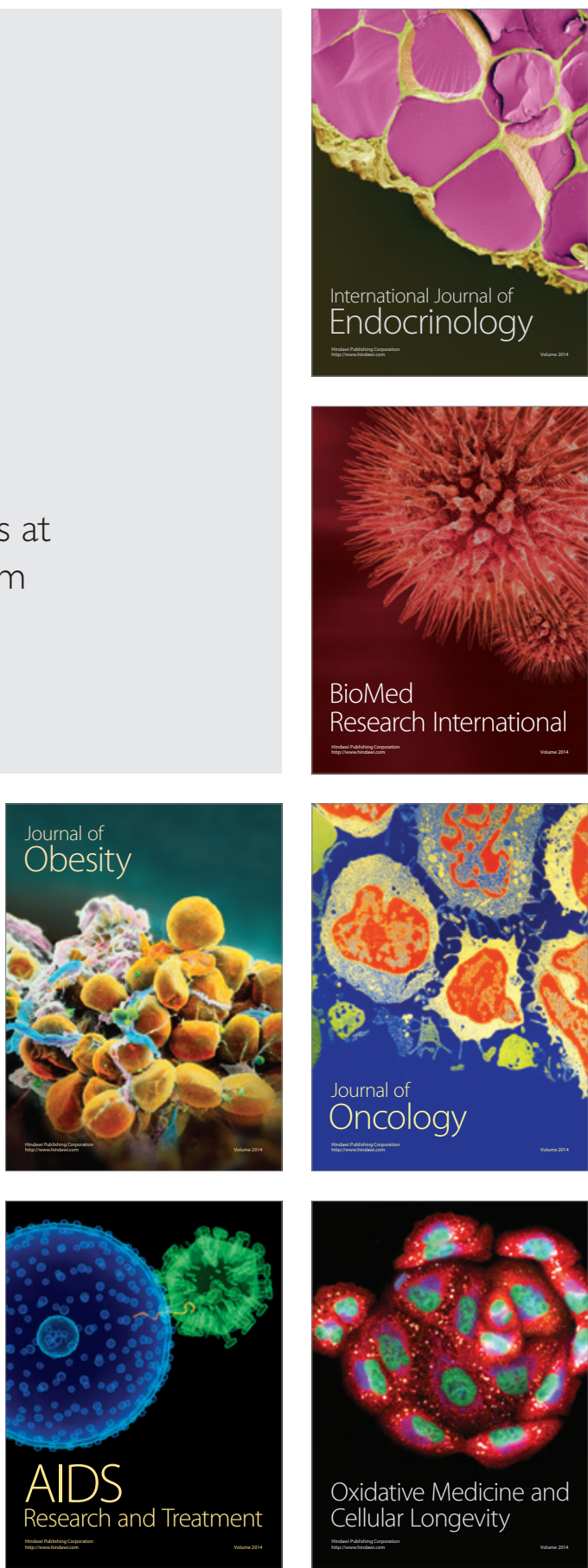